\title{
GMR
}

\section{Effect of gene transfection timing on TGF- $\beta 1$ expression in rabbit mandibular distraction gap}

\author{
M-K. Xie, C-B. Hu, B. Zhou and G-P. Wu \\ Department of Plastic Surgery, \\ The Affiliated Friendship Plastic Hospital of Nanjing Medical University, \\ Nanjing, Jiangsu Province, China \\ Corresponding author: G.-P. Wu \\ E-mail: wuguoping_11@163.com
}

Genet. Mol. Res. 16 (2): gmr16029330

Received September 21, 2016

Accepted February 8, 2017

Published April 13, 2017

DOI http://dx.doi.org/10.4238/gmr16029330

Copyright (C) 2017 The Authors. This is an open-access article distributed under the terms of the Creative Commons Attribution ShareAlike (CC BY-SA) 4.0 License.

ABSTRACT. Transforming growth factor- $\beta 1$ (TGF- $\beta 1$ ) is a member
of the TGF- $\beta$ superfamily, and plays an important role in promoting
various stages of intramembranous and endochondral bone formation.
It is one of the major growth factors that influence new bone formation
in the distraction gap during distraction osteogenesis (DO). The major
problem of DO is the time required for the treatment. Reports show that
gene therapy accelerates osteogenesis, which can significantly benefit
patients with DO. However, the optimal timing of gene transfection has
not yet been reported. In this study, we used the New Zealand rabbit
mandibular DO model for transfecting recombinant plasmid pIRES-
hVEGF165-hBMP2 during the latency, distraction, and consolidation
periods of DO. The TGF- $\beta 1$ levels in the distraction gap were detected
at different time-points by immunohistochemistry and analyzed semi-
quantitatively with the CMIAS-2001A computerized image analyzer.
The TGF- $\beta 1$ levels peaked after 7 days and decreased after 14 days
of consolidation in each group. In contrast, the TGF- $\beta 1$ levels in the
transfected distraction period group were significantly higher than
those in the other groups. After 28 days of consolidation, TGF- $\beta 1$

Genetics and Molecular Research 16 (2): gmr16029330 
levels decreased and there was no significant difference among the groups. These results indicated that the genes transfected in the distraction period up-regulated the expression of $T G F-\beta 1$ more than in the latency and consolidation periods, which promoted bone formation in the distraction gap through a series of biological effects. Thus, we obtained a remarkable effect on new bone formation, and showed that the distraction period is optimal for gene therapy.

Key words: Distraction osteogenesis; Electroporation; Gene therapy; TGF- $\beta 1$

\section{INTRODUCTION}

Distraction osteogenesis (DO) is a method of inducing new bone formation directly from the osteotomy site by gradual distraction of two bone fragments. It was first used to correct mandibular abnormalities and deficiencies in craniofacial surgery (McCarthy et al., 1992). After two decades of clinical usage, craniofacial DO has evolved into a reconstructive technique with expanding applications for the treatment of congenital and acquired bone deficiencies of the facial skeleton. In many specific cases, DO has been a valuable addition to the reconstructive armamentarium of craniofacial surgeons, showing demonstrable advantages over older bone graft and rigid fixation techniques, which includes improved quality of bone regeneration, reduced relapse rates, and concomitant soft-tissue expansion (McCarthy et al., 1992; Carls and Sailer, 1998). Despite the success of DO, several problems have prompted research for improved methods of bone generation. Long consolidation phase is an example of such a limitation, during which the patient has to wear a cumbersome device. In addition, fibrous nonunion may occur due to inadequate neovascularization or from unstable fixation caused by secondary bone infection or device malposition (Carls and Sailer, 1998; Master et al., 2010; Hong et al., 2013). Therefore, both surgeons and patients would welcome any technical improvement that would fasten the treatment process. For example, strategies to accelerate osteogenesis would significantly benefit patients with DO.

In recent years, numerous strategies, including the use of various adjuvant therapies, have been explored for their ability to enhance the maturation of the regenerate bone and reduce the time required to complete DO (Kim and Cho, 2007; Hübler et al., 2010; Xie et al., 2011; Mutlu et al., 2012; Hong et al., 2013; Sun et al., 2014). Several researchers used gene therapy to accelerate bone regeneration (Ashinoff et al., 2004; Hu et al., 2007; Jiang et al., 2010; Lai et al., 2011; Castro-Govea et al., 2012). Our previous studies have confirmed that gene therapy enhanced the proliferation and differentiation of bone mesenchymal stem cells (BMSCs) and promoted new bone formation during DO (Guo-ping et al., 2010; Wu et al., 2012). We also found that the best accelerated bone maturation was obtained when gene transfection was performed during the distraction period (Wu et al., 2013). However, the mechanism is still unclear.

Transforming growth factor- $\beta$ (TGF- $\beta$ ) is a group of multifunctional cytokines that regulate growth, proliferation, adhesion, and apoptosis of various cell types. TGF- $\beta 1$, a member of the TGF- $\beta$ family, is a regulatory protein involved in bone remodeling and fracture healing (Zimmermann et al., 2005; Dimitriou et al., 2005). TGF- $\beta 1$ plays a pivotal role in the process of fracture healing as it enhances the proliferation and differentiation of mesenchymal

Genetics and Molecular Research 16 (2): gmr16029330 
stem cells (MSCs); it also plays an important role in the response of MSCs to mechanical stimulation, increases the production of extracellular matrix, and is chemotactic on bone cells (Kinnaird et al., 2004; Qi et al., 2009). It has a key role in cartilage formation, and increases callus formation and bone strength. Several studies have focused on the roles of cytokines and growth factors in DO. Evidence shows that the local and systemic concentrations of certain cytokines are increased during DO (Weiss et al., 2002, 2005). TGF- $\beta 1$ has been shown to stimulate bone healing in several animal studies and induce bone formation during DO (Koplin et al, 2011; Siwicka et al., 2011; Nuntanaranont et al., 2014). We hypothesize that TGF- $\beta 1$ production and cytokine levels can be modulated by gene transfection at different time-points, thereby affecting new bone formation in the distraction gap. Therefore, we determined the effect of gene transfection at different time-points on the expression of $T G F-\beta 1$ in the distraction gap using the rabbit mandibular DO model.

\section{MATERIAL AND METHODS}

\section{Reagents and instruments}

We constructed the recombinant plasmid pIRES-hVEGF165-hBMP2 (Wu et al., 2007 ) and stored it at $-80^{\circ} \mathrm{C}$. The rabbit anti-TGF- $\beta 1$ antibody, biotin-labeled goat anti-rabbit antibody (IgG), streptavidin-perosidase (SP), 3, 3-diaminobenzidine (DAB) stain kit (Wuhan Boster Biological Technology,Wuhan, China), rabbit mandibular distractor CBX0105-10 (Cixi Cibei Oral Instrument Co. Ltd., China), and the LN-301gene transfection instrument (Tianjin University of Technology, China) were used.

\section{Animal sampling and grouping}

Forty-eight clean New Zealand rabbits $(2.5-3.0 \mathrm{~kg})$ were used in this study. Use of these animals was approved by the Institutional Animal Ethics Committee of Nanjing Medical University, and all experiments were conducted according to the conventions of the Committee for the Purpose of Control and Supervision of Experiments on Animals of China. The rabbits were kept in a dedicated animal holding facility under veterinary supervision in the Laboratory Animal Unit of Nanjing Medical University. The bilateral mandibular DO model was established in these rabbits according to our previous study (Wu et al., 2009). The rabbits were randomly divided into 4 experimental groups with 12 rabbits in each group. In group A, gene transfection was performed immediately after the surgery (latency transfection); in group B, gene transfection was performed after the onset of distraction (distraction stage transfection); in group $\mathrm{C}$, gene transfection was performed after the completion of distraction (consolidation stage transfection); in group D (control group), distraction without gene transfection was performed (non-transfection).

\section{Experimental protocol and distraction}

All rabbits underwent an initial latency period for 3 days while allowing callus formation. On post-operative day 4, distraction was activated at the daily rate of $0.8 \mathrm{~mm}$, which lasted for 10 days. In groups A, B, and C, $2 \mu \mathrm{g}(0.1 \mu \mathrm{g} / \mu \mathrm{L})$ recombinant plasmid pIREShVEGF165-hBMP2 was injected into the distraction area immediately after the surgery, after

Genetics and Molecular Research 16 (2): gmr16029330 
the onset of distraction, and after the completion of activation. After the injection, the animals in all the groups were electroporated. Electrical pulses were generated with a square-wave electroporator LN-301 (Tianjin Technology University, China), which has six 1-mm diameter electrodes surrounded by silicone rubber. The electrodes were punctured into the distraction area. A series of six electrical pulses (each $2 \mathrm{~ms}$ in duration) was administered at the rate of 1 pulse per second at $300 \mathrm{~V}$. The animals in group $\mathrm{D}$ received only the distraction treatment. The treatment protocols were well tolerated by the animals. The device was kept in place until the rabbits were sacrificed.

\section{Tissue processing}

The animals were sacrificed on the 7th, 14th, and 28th day of consolidation. The mandibles were immediately harvested and fixed in $4 \%$ paraformaldehyde for 48 h. Decalcification was performed with sodium citrate/formic acid solutions, which was changed after every 2 days for 14 days. The specimens were dehydrated in ethanol, cleaned with xylene, and subsequently embedded in paraffin. The samples were mounted on an ultramicrotome (PERKIN ELMER Inc.) and sliced into 5- $\mu \mathrm{m}$-thick slices for immunohistochemical staining.

\section{Immunohistochemical stain (SP)}

The paraffin sections were dewaxed with water and washed thrice with $0.01 \mathrm{mM}$ phosphate buffered saline (PBS), $\mathrm{pH} 7.2$, for $5 \mathrm{~min}$. Next, the sections were incubated with $3 \%$ hydrogen peroxide at room temperature for $10 \mathrm{~min}$, and washed thrice with $0.01 \mathrm{mM}$ PBS for $5 \mathrm{~min}$. Antigen repair was performed in citrate buffer in a microwave for $10 \mathrm{~min}$, following which it was cooled naturally and washed thrice with $0.01 \mathrm{mM}$ PBS for $5 \mathrm{~min}$. Next, antibody blocking was performed using goat serum diluted with $0.01 \mathrm{mM}$ PBS and incubated at room temperature for $20 \mathrm{~min}$, following which, the serum was discarded and rabbit anti-TGF- $\beta 1$ antibody (diluted 1:50 -1:100 by 0.01 mM PBS) was added to the samples and incubated at $37^{\circ} \mathrm{C}$ for $1 \mathrm{~h}$, followed by overnight incubation at $4^{\circ} \mathrm{C}$. The next day, the samples were washed thrice with $0.01 \mathrm{mM}$ PBS for $5 \mathrm{~min}$. Biotin-labeled goat anti-rabbit $\operatorname{IgG}$ (diluted 1:100 by $0.01 \mathrm{mM}$ PBS) secondary antibody was added and incubated at $37^{\circ} \mathrm{C}$ for $1 \mathrm{~h}$. Then, the samples were washed thrice with $0.01 \mathrm{mM}$ PBS for $5 \mathrm{~min}$. Next, SP (diluted 1: 100 by 0.01 $\mathrm{mM}$ PBS) was added to the samples and incubated at $37^{\circ} \mathrm{C}$ for $1 \mathrm{~h}$. Subsequently, the samples were washed thrice with $0.01 \mathrm{mM}$ PBS for $5 \mathrm{~min}$, colored with $\mathrm{DAB}$, and observed under the microscope. The nuclei were stained by hematoxylin followed by dehydration, and mounting. PBS alone was used instead of the primary antibody in the control group. Brown cytoplasm or nuclei and light blue nuclei were considered as positive results.

\section{Image analysis and quantitation}

Five slices were randomly selected from each specimen. The mean optical density (MOD) and integral optical density (IOD) of the cells expressing TGF- $\beta 1$ were randomly detected using the CMIAS series multi-function true color pathological image analysis system (Beijing Mike Audi Image Technology Co., Ltd., Beijing, China) under the 10 X 40 fields of the light microscope. The data are reported as means \pm standard deviation (means $\pm \mathrm{SD}$ ).

Genetics and Molecular Research 16 (2): gmr16029330 


\section{Statistical analysis}

The mean optical density (MOD) and integral optical density (IOD) of TGF- $\beta 1$ in the mandibular distraction gap of the 4 groups were statistically analyzed by pairwise comparison using the Statistical Package for Social Sciences software, version 17.0 (Chicago, IL, USA). All data are reported as means $\pm \mathrm{SD}$. The single factor analysis of variance and the $\mathrm{Q}$ test were used to compare the sample means. $\mathrm{P}<0.05$ was considered significant.

\section{RESULTS}

\section{Observation on gross}

All the animals tolerated the osteotomy and distraction protocol, and presented with mild eating disorder without significant change in weight. Cross-bites were observed on all the animals after the distraction (Figure 1). All the distraction devices were found to be intact and in place at the time of sacrifice. Fibrous connective tissue was observed in the distraction gap on the 7th day after the distraction, and the distraction gap was completely bent. On the 14th day, a large number of new bone formation mixed with fibrous connective tissue appeared in the distraction gap, and the distraction gap could be partially bent (Figure 2). On the 28th day of consolidation, the distraction gaps were filled with large numbers of calluses; the surface of the calluses were smooth on both the buccal and lingual side of the mandibles in the animals of groups B and C, whereas these were still uneven with depression or bulging in the animals of groups A and D.

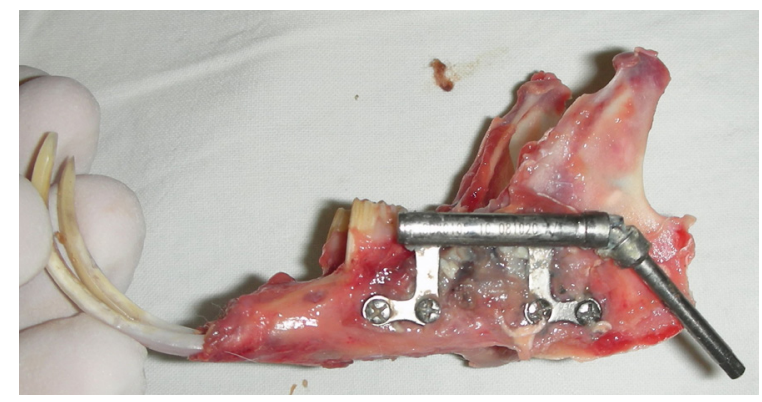

Figure 1. Gross appearance of the mandible, demonstrating overgrowth of the lower incisor.

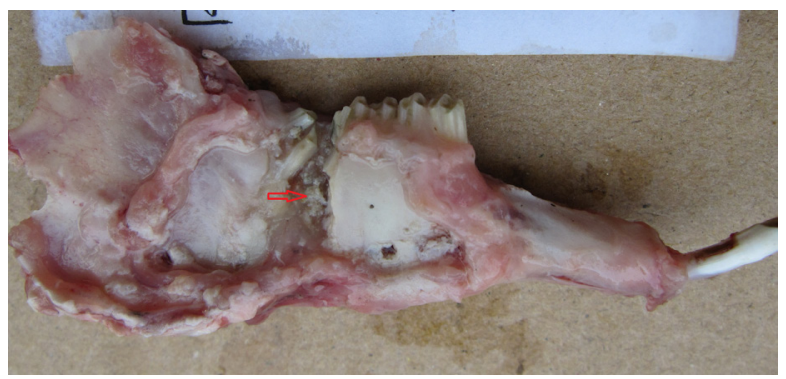

Figure 2. Morphological features of the distraction gap on the 14th day. New bone formation, mixed with growth of fibrous connective tissue, was observed in the distraction gap (marked with red arrow). The distraction gap could be partially bent. 


\section{TGF- $\beta 1$ expression}

Immunohistochemical analysis of the distraction gap tissue sections showed that $T G F-\beta 1$ was expressed in all the mandible specimens at all time points. The spatial localization of TGF- $\beta 1$ is presented in Figures 3-5. On the 7th day of consolidation, TGF- $\beta 1$ was highly expressed in fibroblast, osteocytes, osteoblasts, and chondrocytes in the middle of the distraction gap, and in large numbers of unclear mesenchymal cells adjacent to the host bone (Figure 3). On the 14th day, TGF- $\beta 1$ staining was found mainly in the cytoplasm of hypertrophic chondrocytes and osteoblastic cells, rimming the trabecular bones arranged along the stretching direction within the distraction regenerate callus (Figure 4). On the 28th day, the TGF- $\beta 1$ was detected mainly in the osteoblasts of the callus surface and the osteocytes of new woven bone callus, although the population of these cells decreased gradually (Figure 5 ). The MOD and IOD of TGF- $\beta 1$ of the four groups at different time-points were calculated and are listed in Table 1. Semi-quantitative analysis showed that the expression of TGF- $\beta 1$ peaked on the 7 th day of consolidation in all the groups. Compared to the expression observed in the other three groups, the expression of TGF- $\beta 1$ in group B $(0.37 \pm 0.07,0.90 \pm 0.06)$ was significantly higher than those in groups $\mathrm{A}(0.16 \pm 0.05,0.41 \pm 0.03), \mathrm{C}(0.22 \pm 0.02$, $0.69 \pm 0.02)$, and $\mathrm{D}(0.11 \pm 0.03,0.21 \pm 0.04)(\mathrm{P}<0.01, \mathrm{P}<0.05)$. The number of positive cells decreased on the 14th day of consolidation. The expression of TGF- $\beta 1$ in group $\mathrm{B}$ was significantly different from those of groups $\mathrm{A}, \mathrm{C}$, and $\mathrm{D}(\mathrm{P}<0.05)$. The expression of $T G F-\beta 1$ was low after 28 days of consolidation, and there was no significant difference among the different groups $(\mathrm{P}>0.05)$.
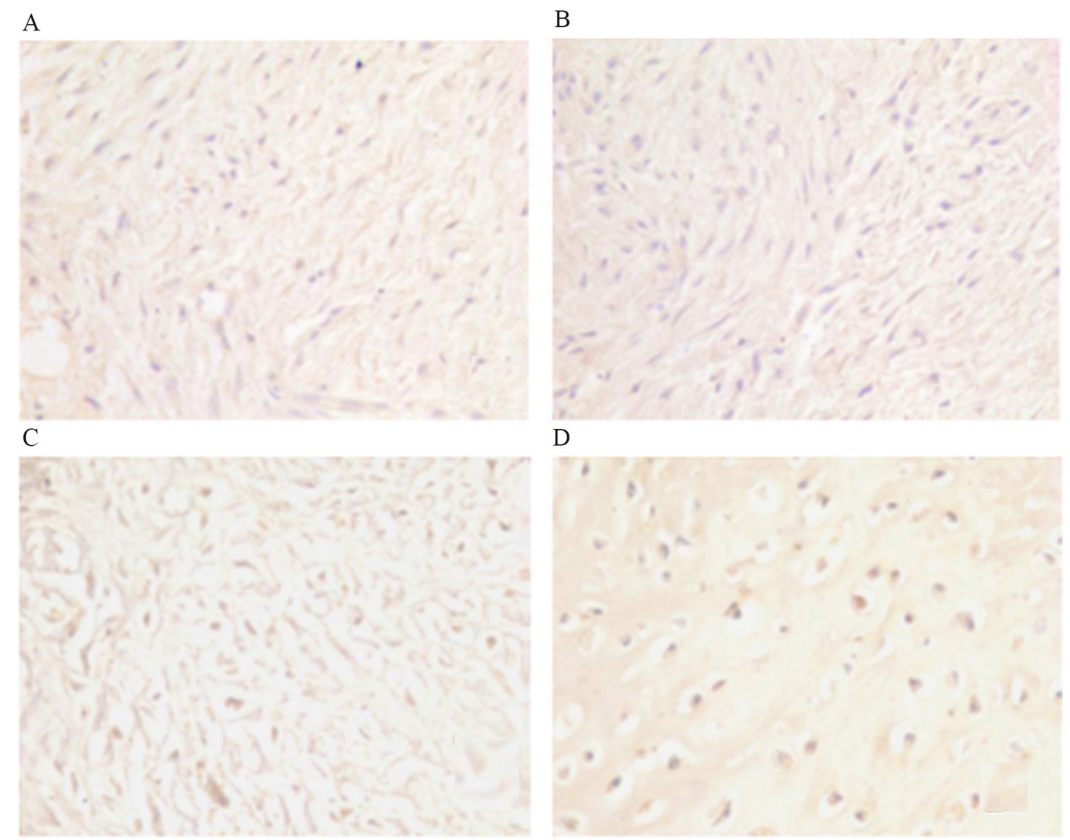

Figure 3. TGF- $\beta 1$ levels on the 7th day of the consolidation period were measured with immunohistochemistry staining. (streptavidin-perosidase, $400 \mathrm{X}$ ). A. Group A: Transfection at latency stage. B. Group B: Transfection at distraction stage. C. Group C: Transfection at consolidation stage. D. Group D: Control group (non-transfected).

Genetics and Molecular Research 16 (2): gmr16029330 

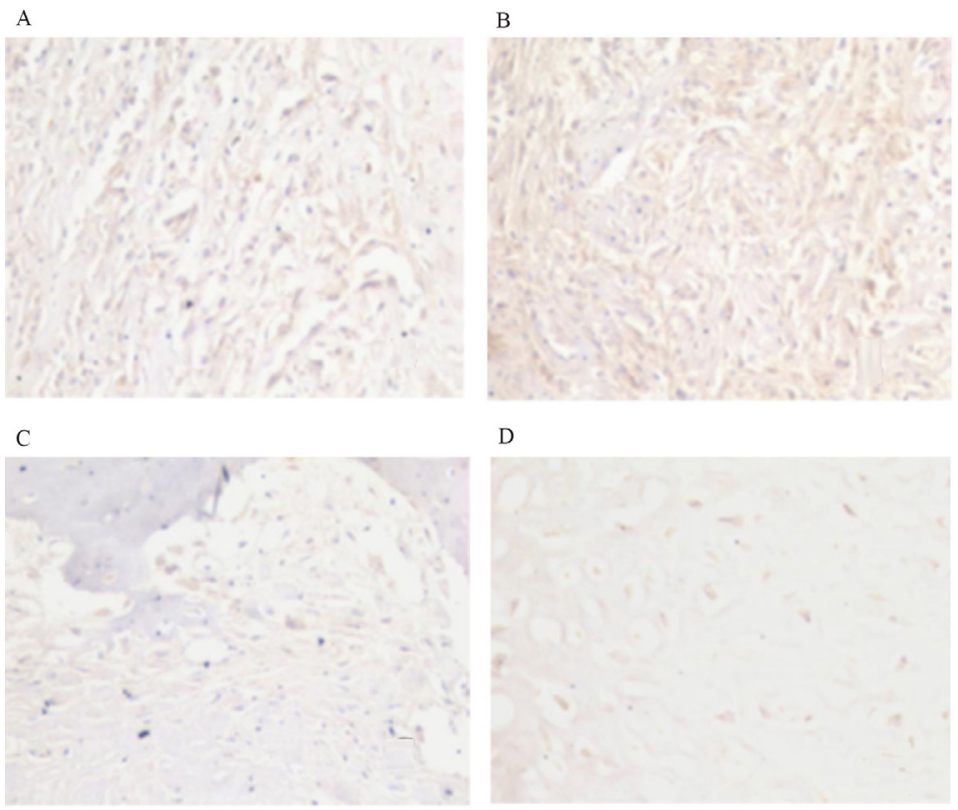

$\mathrm{D}$

Figure 4. TGF- $\beta 1$ levels on the 14th day of the consolidation period were measured with immunohistochemistry staining. (streptavidin-perosidase, $400 \mathrm{X}$ ). A. Group A: Transfection at latency stage. B. Group B: Transfection at distraction stage. C. Group C: Transfection at consolidation stage. D. Group D: Control group (non-transfected).
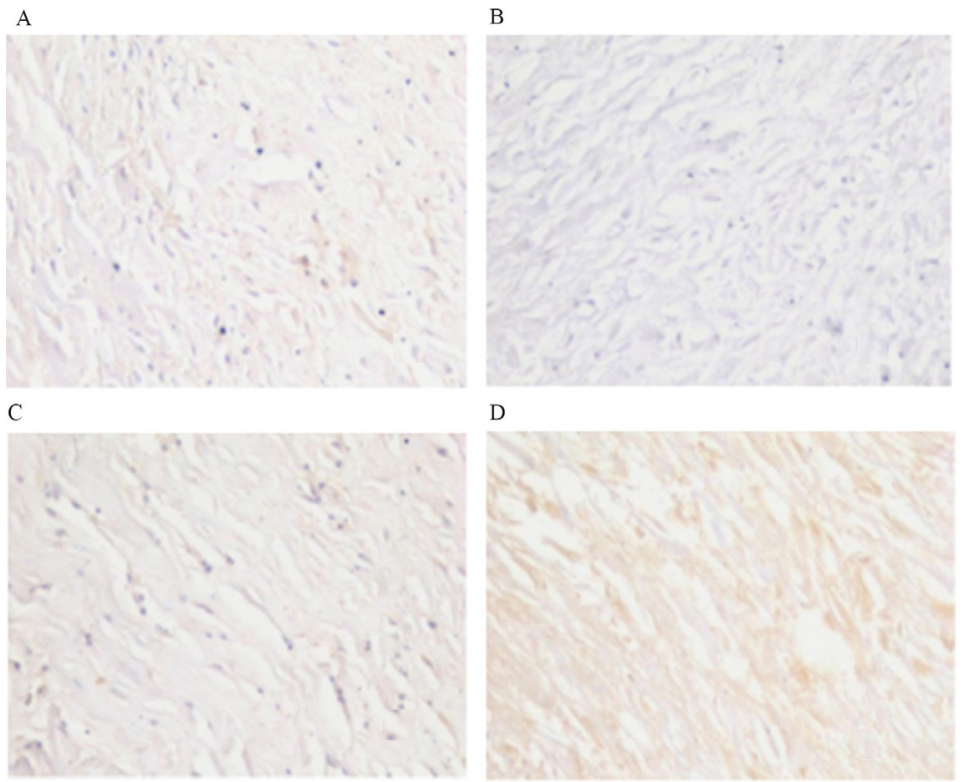

Figure 5. TGF- $\beta 1$ levels on the 28th day of the consolidation period were measured with immunohistochemistry staining. (streptavidin-perosidase, 400X). A. Group A: Transfection at latency stage. B. Group B: Transfection at distraction stage. C. Group C: Transfection at consolidation stage. D. Group D: Control group (non-transfected).

Genetics and Molecular Research 16 (2): gmr16029330 
Table 1. Mean optical density and integrated optical density of TGF- $\beta 1$ (means \pm SD).

\begin{tabular}{l|c|c|c|c|c|c}
\hline \multirow{2}{*}{ Group } & \multicolumn{2}{|c|}{ 7 days } & \multicolumn{2}{c|}{ 14 days } & \multicolumn{2}{c}{28 days } \\
\cline { 2 - 7 } & MOD & IOD & MOD & IOD & MOD & $0.33 \pm 0.03$ \\
\hline A & $0.16 \pm 0.05$ & $0.41 \pm 0.03$ & $0.14 \pm 0.04$ & $0.47 \pm 0.05$ & $0.10 \pm 0.02$ & $0.34 \pm 0.02$ \\
\hline B & $0.37 \pm 0.07$ & $0.90 \pm 0.06$ & $0.29 \pm 0.06$ & $0.82 \pm 0.08$ & $0.12 \pm 0.03$ & $0.33 \pm 0.03$ \\
\hline C & $0.22 \pm 0.02$ & $0.69 \pm 0.02$ & $0.19 \pm 0.05$ & $0.66 \pm 0.01$ & $0.11 \pm 0.04$ & $0.26 \pm 0.01$ \\
\hline D & $0.11 \pm 0.03$ & $0.21 \pm 0.04$ & $0.09 \pm 0.02$ & $0.28 \pm 0.02$ & $0.08 \pm 0.02$ & 0.02
\end{tabular}

Group A: Transfection performed at latency stage; Group B: Transfection performed at distraction stage; Group C: Transfection performed at consolidation stage; Group D: control group (non-transfected). MOD: mean optical density. IOD: integrated optical density.

\section{DISCUSSION}

Since its introduction in 1992 to correct hemifacial hypoplasia malformations (McCarthy et al., 1992), DO has been widely used in craniomaxillofacial surgery. The benefits of DO include the avoidance of bone grafting and donor-site morbidity, availability for use in surgery on younger patients, and the concurrent expansion of the soft-tissue envelope, which reduces the recurrence rate. However, DO requires a long-term consolidation for complete ossification in the distracted bone gap. The distraction devices must be kept in place not only during the distraction but also during the consolidation period, which may lead to infection, and be difficult to endure (Carls and Sailer, 1998; Master et al., 2010; Hong et al., 2013). Therefore, strategies that can accelerate osteogenesis would significantly benefit the patients. In recent years, some researchers have been able to successfully accelerate bone regeneration by gene therapy (Ashinoff et al., 2004; Hu et al., 2007; Jiang et al., 2010; Lai et al., 2011; Castro-Govea et al., 2012). Ashinoff et al. (2004) applied the adenovirus-mediated BMP-2 (AdBMP-2) gene therapy for DO, and demonstrated that it could increase bone deposition, shorten consolidation, and enhance DO in poorly healing mandibles. Hu et al. (2007) revealed that BMP-7 ex vivo gene therapy enhanced bone formation during DO in rats. CastroGovea et al. (2012) demonstrated an acceleration of osteogenesis during bone distraction in dogs using an implant of BMP-2 modified MSCs. Jiang and colleagues (2010) used MSCs transfected with $b F G F$ to demonstrate enhanced bone healing in a rabbit model of mandibular DO. The effect of MSCs on mandibular distraction osteogenesis(MDO) with or without the osterix-encoding gene was reported by Lai et al. (2011). Although MSCs alone demonstrated favorable outcomes, the osterix-mediated gene therapy was found to be the more effective in promoting bone maturation. In our previous study we demonstrated that electroporationmediated plasmid (pIRES-hBMP-2-hVEGF165) transfection promoted new bone formation and mineral deposition, and increased the stiffness of the new bone in the distraction gap during DO in vivo. In addition, we obtained remarkable effects on new bone formation when the genes were transfected at the beginning of the traction (distraction period) than at other stages of DO (Wu et al., 2012; Wu et al., 2013). These results would be helpful for future clinical trials of mandible bone distraction. However, these studies focused only on the evaluation of different biological parameters, whereas the molecular mechanisms of gene therapy and its downstream effects remain unclear. Understanding of the molecular mechanisms would reveal the optimal amount, time, and method of transfection, which would help achieve the most favorable effect.

In this study, TGF- $\beta 1$ was expressed highly in fibroblasts, osteocytes, osteoblasts, and chondrocytes in the middle of the distraction gap, and in many unclear mesenchymal cells adjacent to the host bone, which peaked on the 7th day of consolidation in all the groups. In

Genetics and Molecular Research 16 (2): gmr16029330 
group $\mathrm{B}$, the expression of $T G F-\beta 1$ was higher than that in the other three groups on the 7 th and 14th days of the consolidation period. With the prolonging of consolidation, the expression of $T G F-\beta 1$ gradually decreased, and on the 28th day of the consolidation period, there was no significant difference among the four groups. This suggested that gene transfection performed during the distraction period lead to higher expression of $T G F-\beta 1$ than in the other two periods, and therefore, the distraction period is optimal for gene transfection. This may be explained as follows. The latency period is similar to the early stages of bone fracture healing when blood or exudate is present in the osteotomy site immediately after the surgery. Since the proliferative ability of the osteoblasts is relatively weak at this time, the repair response to the injury occurs predominantly in the distraction area (Ai-Aql et al., 2008). Therefore, the plasmid injected into the gap during the latency period may be diluted or washed away by the blood and exudate, and the inflammatory mediator release responses to the injury may influence the efficiency of transfection. After activation of the distraction device, the distraction stress eventually affects the mesenchymal cells and osteoblasts in the distraction gap via a series of complex internal and external cell signaling transduction pathways (Zhuang et al., 1996; Weyts et al., 2003). At this time-point, the transfected gene may alter the expression of the key proteins of the TGF- $\beta /$ Smad signal transduction pathway and promote cell proliferation and gene expression. Subsequently, this may induce entry into mitosis, and osteogenic factors could maximize the effects on new bone formation and osteoblast proliferation. Meanwhile, osteoblasts may secrete more TGF- $\beta 1$ (Kletsas et al., 2002; Kanno et al., 2005, 2007), which may increase active bone formation through signal transduction. Therefore, the expression of $T G F-\beta 1$ was the strongest on the 7th day of the consolidation period. The cells in the gap proliferated actively and added new cells, and the stroma continuously satisfied the requirements of rapid new bone regeneration in the distraction gap. In our previous study, we demonstrated that the biomechanical parameters of the new bone formed in the distraction gap of the animals in the distraction period gene transfection group were higher than those observed in the other two periods (Wu et al, 2013). Although the distraction tension stimulation was eliminated during the consolidation phase, large number of cells were required to complete osteogenesis in the gap, which was achieved by increased activity of the osteoblasts and elevated levels of the secreted cytokines in the consolidation phase. Since new bone formation in the distraction area was predominated by matrix mineralization, the osteoblasts were packaged by the matrix and did not synthesize or secrete any further (Ai-Aql et al., 2008). The expression and secretion of TGF- $\beta 1$ from the transfected cells was reduced and the bio-effect induced by TGF- $\beta 1$ was lower when gene transfection was performed in the consolidation period. Therefore, in the group where gene transfection was performed during the consolidation period, TGF- $\beta 1$ levels were lower than that in the distraction period. On the 28th day of the consolidation period, the distraction gap was mainly composed of mineralized matrix and molded callus. Although the TGF- $\beta 1$ levels decreased, it was still weakly positive until the normal level was reached.

In summary, our study demonstrated that electroporation-mediated transfection of plasmid pIRES-hBMP-2-hVEGF165 up-regulated the expression of $T G F-\beta 1$, which increased new bone formation. However, the effects varied with the time of transfection. We found that transfection performed at the beginning of traction (distraction period) than at other stages of DO produced better effects on bone formation, possibly because of the existing tension signals and the increase in expression of growth factor-encoding genes that are regulated by the Smad/TGF- $\beta$ signaling pathway. This possibly caused the pathways to operate in an "open" state in the distraction gap, which enhanced the transfection efficiency, and therefore,

Genetics and Molecular Research 16 (2): gmr16029330 
showed remarkable effects on new bone formation, suggesting that the distraction stage is the optimal time for gene therapy. However, the use of electroporation is a limitation of this study. Although it induces efficient transfection with less toxicity, electroporation causes pain and strong muscle twitching during application of the electric field due to nerve stimulation; additionally, it requires a high-voltage source to generate sufficient electric field strength for electroporation and can cause tissue damage due to the high electric current. Future experiments are warranted to address the effect of high electric current on aberrant expression of the target gene more precisely.

\section{Conflicts of interest}

The authors declare no conflict of interest.

\section{REFERENCES}

Ai-Aql ZS, Alagl AS, Graves DT, Gerstenfeld LC, et al. (2008). Molecular mechanisms controlling bone formation during fracturehealing and distractionosteogenesis.J.Dent.Res. 87:107-118.http://dx.doi.org/10.1177/154405910808700215

Ashinoff RL, Cetrulo Jr CL, Galiano RD, Dobryansky M, et al. (2004). Bone morphogenic protein-2 gene therapy for mandibular distraction osteogenesis. Ann. Plast. Surg. 52: 585-590, discussion 591. http://dx.doi.org/10.1097/01. $\underline{\text { sap.0000123023.28874.1e }}$

Carls FR and Sailer HF (1998). Seven years clinical experience with mandibular distraction in children. J. Craniomaxillofac. Surg. 26: 197-208. http://dx.doi.org/10.1016/S1010-5182(98)80015-2

Castro-Govea Y, Cervantes-Kardasch VH, Borrego-Soto G, Martínez-Rodríguez HG, et al. (2012). Human bone morphogenetic protein 2-transduced mesenchymal stem cells improve bone regeneration in a model of mandible distraction surgery. J. Craniofac. Surg. 23: 392-396. http://dx.doi.org/10.1097/SCS.0b013e318240fe9b

Dimitriou R, Tsiridis E and Giannoudis PV (2005). Current concepts of molecular aspects of bone healing. Injury 36: 1392-1404. http://dx.doi.org/10.1016/j.injury.2005.07.019

Guo-ping W, Xiao-chuan H, Zhi-hui Y and Li G (2010). Influence on the osteogenic activity of the human bone marrow mesenchymal stem cells transfected by liposome-mediated recombinant plasmid pIRES-hBMP2-hVEGF165 in vitro. Ann. Plast. Surg. 65: 80-84. http://dx.doi.org/10.1097/SAP.0b013e3181b4bc5d

Hübler R, Blando E, Gaião L, Kreisner PE, et al. (2010). Effects of low-level laser therapy on bone formed after distraction osteogenesis. Lasers Med. Sci. 25: 213-219. http://dx.doi.org/10.1007/s10103-009-0691-2

Hong P, Boyd D, Beyea SD and Bezuhly M (2013). Enhancement of bone consolidation in mandibular distraction osteogenesis: a contemporary review of experimental studies involving adjuvant therapies. J. Plast. Reconstr. Aesthet. Surg. 66: 883-895. http://dx.doi.org/10.1016/j.bjps.2013.03.030

Hu J, Qi MC, Zou SJ, Li JH, et al. (2007). Callus formation enhanced by BMP-7 ex vivo gene therapy during distraction osteogenesis in rats. J. Orthop. Res. 25: 241-251. http://dx.doi.org/10.1002/jor.20288

Jiang X, Zou S, Ye B, Zhu S, et al. (2010). bFGF-Modified BMMSCs enhance bone regeneration following distraction osteogenesis in rabbits. Bone 46: 1156-1161. http://dx.doi.org/10.1016/j.bone.2009.12.017

Kim JY and Cho BC (2007). Effect of calcium sulfate pellets on early bone mineralization in distraction osteogenesis for craniofacial microsomia in adults. J. Craniofac. Surg. 18: 1309-1321. http://dx.doi.org/10.1097/ $\underline{\text { SCS.0b013e3180a771c6 }}$

Kanno T, Takahashi T, Ariyoshi W, Tsujisawa T, et al. (2005). Tensile mechanical strain up-regulates Runx2 and osteogenic factor expression in human periosteal cells: implications for distraction osteogenesis. J. Oral Maxillofac. Surg. 63: 499-504. http://dx.doi.org/10.1016/j.joms.2004.07.023

Kanno T, Takahashi T, Tsujisawa T, Ariyoshi W, et al. (2007). Mechanical stress-mediated Runx2 activation is dependent on Ras/ERK1/2 MAPK signaling in osteoblasts. J. Cell. Biochem. 101: 1266-1277. http://dx.doi.org/10.1002/jcb.21249

Kinnaird T, Stabile E, Burnett MS, Lee CW, et al. (2004). Marrow-derived stromal cells express genes encoding a broad spectrum of arteriogenic cytokines and promote in vitro and in vivo arteriogenesis through paracrine mechanisms. Circ. Res. 94: 678-685. http://dx.doi.org/10.1161/01.RES.0000118601.37875.AC

Kletsas D, Basdra EK and Papavassiliou AG (2002). Effect of protein kinase inhibitors on the stretch-elicited c-Fos and c-Jun up-regulation in human PDL osteoblast-like cells. J. Cell. Physiol. 190: 313-321. http://dx.doi.org/10.1002/jcp.10052

Genetics and Molecular Research 16 (2): gmr16029330 
Koplin SA, Su L, Salamat S, Torrealba J, et al. (2011). Distraction osteogenesis-induced muscle fibrosis may not be associated with TGF-b1. J. Pediatr. Orthop. 31: 413-420. http://dx.doi.org/10.1097/BPO.0b013e31821adc8d

Lai QG, Yuan KF, Xu X, Li DR, et al. (2011). Transcription factor osterix modified bone marrow mesenchymal stem cells enhance callus formation during distraction osteogenesis. Oral Surg. Oral Med. Oral Pathol. Oral Radiol. Endod. 111: 412-419. http://dx.doi.org/10.1016/j.tripleo.2010.05.012

McCarthy JG, Schreiber J, Karp N, Thorne CH, et al. (1992). Lengthening the human mandible by gradual distraction. Plast. Reconstr. Surg. 89: 1-8, discussion 9-10. http://dx.doi.org/10.1097/00006534-199289010-00001

Master DL, Hanson PR and Gosain AK (2010). Complications of mandibular distraction osteogenesis. J. Craniofac. Surg. 21: 1565-1570. http://dx.doi.org/10.1097/SCS.0b013e3181ecc6e5

Mutlu I, Aydintug YS, Kaya A, Bayar GR, et al. (2012). The evaluation of the effects of hyperbaric oxygen therapy on new bone formation obtained by distraction osteogenesis in terms of consolidation periods. Clin. Oral Investig. 16: 1363-1370. http://dx.doi.org/10.1007/s00784-011-0644-6

Nuntanaranont T, Suttapreyasri S and Vongvatcharanon S (2014). Quantitative expression of bone-related cytokines induced by mechanical tension-stress during distraction osteogenesis in a rabbit mandible. J. Investig. Clin. Dent. 5: 255-265. http://dx.doi.org/10.1111/jicd.12034

Qi MC, Zou SJ, Han LC, Zhou HX, et al. (2009). Expression of bone-related genes in bone marrow MSCs after cyclic mechanical strain: implications for distraction osteogenesis. Int. J. Oral Sci. 1: 143-150. http://dx.doi.org/10.4248/ IJOS.09021

Siwicka KA, Kitoh H, Kawasumi M and Ishiguro N (2011). Spatial and temporal distribution of growth factors receptors in the callus: implications for improvement of distraction osteogenesis. Nagoya J. Med. Sci. 73: 117-127.

Sun JJ, Zheng XH, Wang LY, Liu L, et al. (2014). New bone formation enhanced by ADSCs overexpressing hRunx2 during mandibular distraction osteogenesis in osteoporotic rabbits. J. Orthop. Res. 32: 709-720. http://dx.doi.org/10.1002/ jor. 22590

Weiss S, Baumgart R, Jochum M, Strasburger CJ, et al. (2002). Systemic regulation of distraction osteogenesis: a cascade of biochemical factors. J. Bone Miner. Res. 17: 1280-1289. http://dx.doi.org/10.1359/jbmr.2002.17.7.1280

Weiss S, Zimmermann G, Baumgart R, Kasten P, et al. (2005). Systemic regulation of angiogenesis and matrix degradation in bone regeneration--distraction osteogenesis compared to rigid fracture healing. Bone 37: 781-790. http://dx.doi. org/10.1016/j.bone.2005.06.014

Weyts FA, Bosmans B, Niesing R, van Leeuwen JP, et al. (2003). Mechanical control of human osteoblast apoptosis and proliferation in relation to differentiation. Calcif. Tissue Int. 72: 505-512. http://dx.doi.org/10.1007/s00223-002$\underline{2027-0}$

Wu GP, He XC, Hu CB, Li DP, et al. (2012). Effect of electroporation-mediated transfecting recombinant plasmid pIRES-hBMP2-hVEGF165 on mandibular distraction osteogenesis. Ann. Plast. Surg. 69: 316-325. http://dx.doi. org/10.1097/SAP.0b013e3182119275

Wu G, Hu C, He X, Yin K, et al. (2013). Effect of gene transfecting at different times on mandibular distraction osteogenesis. J. Craniofac. Surg. 24: 232-236. http://dx.doi.org/10.1097/SCS.0b013e31826cff2a

Wu GP, Teng L, Gui L, Lu JJ, et al. (2007). The coexpression of human bone morphogenetic protein-2 and vascular endothelial growth factor -165 in human bone marrow mesenchymal stem cells. Zhongguo Zuzhi Gongcheng Yanjiu yu Linchuang Kangfu 11: 587-591.

Wu GP, Li SH, Li DP, Yang ZH, et al. (2009). Establishment of animal model for electroporation-mediated gene therapy in distraction osteogenesis of rabbit mandible. Zhonghua Zheng Xing Wai Ke Za Zhi 25: 280-283.

Xie LK, Wangrangsimakul K, Suttapreyasri S, Cheung LK, et al. (2011). A preliminary study of the effect of low intensity pulsed ultrasound on new bone formation during mandibular distraction osteogenesis in rabbits. Int. J. Oral Maxillofac. Surg. 40: 730-736. http://dx.doi.org/10.1016/j.ijom.2011.03.016

Zhuang H, Wang W, Tahernia AD, Levitz CL, et al. (1996). Mechanical strain-induced proliferation of osteoblastic cells parallels increased TGF-beta 1 mRNA. Biochem. Biophys. Res. Commun. 229: 449-453. http://dx.doi.org/10.1006/ bbrc. 1996.1824

Zimmermann G, Henle P, Küsswetter M, Moghaddam A, et al. (2005). TGF-beta1 as a marker of delayed fracture healing. Bone 36: 779-785. http://dx.doi.org/10.1016/j.bone.2005.02.011

Genetics and Molecular Research 16 (2): gmr16029330 